\title{
Assessment of Sesamia nonagrioides (Lepidoptera: Noctuidae) $E c R$ and USP Genes as Targets for Exogenous Non-Persistent RNAi
}

\author{
Dimitrios Kontogiannatos $^{1,2, * \mathbb{D}}$, Luc Swevers ${ }^{2} \mathbb{D}$ and Anna Kourti ${ }^{1, *}$ \\ 1 Department of Biotechnology, School of Food, Biotechnology and Development, \\ Agricultural University of Athens, 11855 Athens, Greece \\ 2 Insect Molecular Genetics and Biotechnology Group, National Centre for Scientific Research "Demokritos", \\ Institute of Biosciences \& Applications, 15341 Athens, Greece; swevers@bio.demokritos.gr \\ * Correspondence: dimkonto@bio.demokritos.gr (D.K.); akourti@aua.gr (A.K.)
}

check for updates

Citation: Kontogiannatos, D.;

Swevers, L.; Kourti, A. Assessment of Sesamia nonagrioides (Lepidoptera: Noctuidae) EcR and USP Genes as Targets for Exogenous Non-Persistent RNAi. Diversity 2021, 13, 677. https://doi.org/10.3390/d13120677

Academic Editor: Michael Wink

Received: 16 November 2021 Accepted: 16 December 2021 Published: 17 December 2021

Publisher's Note: MDPI stays neutra with regard to jurisdictional claims in published maps and institutional affiliations.

Copyright: (c) 2021 by the authors. Licensee MDPI, Basel, Switzerland. This article is an open access article distributed under the terms and conditions of the Creative Commons Attribution (CC BY) license (https:// creativecommons.org/licenses/by/ $4.0 /)$.

\begin{abstract}
RNA interference (RNAi) is a transforming technology with high potential for practical applications in biology, including specific and safe insect pest control. For developing RNAi-based pest-control products no general recommendations exist and the best strategy needs to be determined for each insect pest separately on a case-by-case basis. In this research, the potential of silencing the genes encoding the subunits of the ecdysone receptor complex, EcR and Ultraspiracle (USP) by RNAi was evaluated in the corn borer, Sesamia nonagrioides, using different delivery approaches and targeting different developmental stages. In conjunction with our previous research it is demonstrated that prepupae are sensitive to RNAi triggered by dsRNA injection and that feeding of dsRNA-expressing bacteria throughout $S$. nonagrioides' larval life can lead to limited developmental malformations with no potent insecticidal results. Our results, consistent with previous studies, indicated a great fluctuation of exogenous RNAi effectiveness in the Lepidopteran species, suggesting that further factors should be taken into consideration in order to expand this very promising field into the "RNAi-resistant" insect species.
\end{abstract}

Keywords: RNAi; Sesamia nonagrioides; ecdysone receptor; EcR; Ultraspiracle gene; USP; RNAi resistance

\section{Introduction}

An evolutionary conserved mechanism of eukaryotic cells (known as RNA interference, RNAi) to regulate post-transcriptional gene expression triggered by double-stranded RNA (dsRNA) molecules [1] is considered as a spearhead for innovative technologies with future applications in Green and Red biotechnology. RNAi is well-known as a cellular defense mechanism in animals and plants against RNA viruses and exogenously uptaken dsRNA molecules [2]. A similar mechanism is used by endogenously expressed microRNAs (miRNAs) to regulate gene expression by pairing with mRNAs of protein-coding genes to direct their post-transcriptional repression [3].

In the nematode Caenorhabditis elegans, gene-specific downregulation is initiated when dsRNA molecules are simply taken up through their digestive system [4]. Similarly, RNAi can be induced in C. elegans by feeding with the RNaseIII deficient HT115 Escherichia coli strain, which is able to produce high quantities of specific dsRNAs in vivo [4]. One of the first reports that demonstrated RNAi in insects - using a cell-free system-was published in 1999. In this report, a cell-free system based in the syncytial blastoderm of Drosophila melanogaster embryos was developed and recapitulated many of the features of RNAi; the interference was sequence specific, was promoted by dsRNA but not single-stranded RNA, and required a minimum length of dsRNA [5]. In further studies it was revealed that, in genetically modified D. melanogaster, expressed dsRNAs from an extended hairpinloop RNA transgene, conferred specific interference of gene expression in embryos and 
tissues influencing the formation of adult structures such as wings, legs, eyes, and brain [6]. Moreover, it was observed that RNAi can be induced in adult fruit flies simply by injecting dsRNAs into their abdomen [7]. This method would also find applications in targeting distantly expressed genes like those that are expressed in the central nervous system (CNS) of D. melanogaster [7].

Following D. melanogaster, RNAi was found to be successful in other insect species. For instance, the first report of successful RNAi in a lepidopteran insect was documented in Spodoptera litura larvae in which administration of aminopeptidase's slapn dsRNAs to their hemolymph caused reduced slapn gene expression and decreased sensitivity to the Cry1C toxin [8]. The previous progress towards RNAi research created hopes that oral dsRNA uptake could also regulate gene expression in insects. Indeed, this approach was proven to be feasible in a following research when ingested dsRNAs of the salivary nitrophorin 2 (NP2) gene by the triatomine insect Rhodnius prolixus were shown to significantly inhibit NP2 gene expression [9].

The progress toward the aforementioned breakthroughs led to the ground-breaking publications that showed the feasibility of using RNAi technology in the control of insect pests of crops $[10,11]$. These publications demonstrated that genetically modified plants expressing dsRNAs of an entomological origin could be influencing the development and growth of phytophagous insect species that were feeding on them. Corn plants expressing hairpin dsRNAs that target the A subunit of the ATPase gene of Diabrotica virgifera virgifera (western corn rootworm, WCR), were proven to be significantly protected from being damaged by them [10]. In addition, Arabidopsis thaliana plants expressing double-stranded RNA hairpins targeting the cytochrome P450 monooxygenase gene of the corn pest Helicoverpa armigera decreased the resistance of this insect species against the sesquiterpene gossypol [11]. At this point onwards numerous publications were documenting the feasibility of the RNAi approach in gene silencing of a wide range of insect families belonging to the classes of Coleoptera, Diptera, Dictyoptera, Hemiptera, Hymenoptera, Isoptera, Lepidoptera, Neuroptera and Orthoptera (reviewed by Baum and Roberts, 2014 [12]). In the continuous flow of insect-related RNAi publications, the first reports regarding bacteria-mediated RNAi targeting the beet armyworm Spodoptera exigua and the oriental fruitfly Bactrocera dorsalis were published [13,14].

Nowadays, RNAi is considered as one of the most promising technologies to be used in the pesticide industry. RNAi technology provides an alternative, selective to species level, environmentally friendly strategy to combat insect pests. RNAi seems to be the ideal option to overcome obstacles emerging from the conventional pesticide industry. Most of the dsRNA delivering methodologies studied so far involve injection or feeding of in vitro synthesized or bacterially expressed dsRNAs, feeding of plant tissues over-expressing dsRNAs, and infection with dsRNA expressing recombinant insect viruses [15]. For RNAi to be functional, dsRNAs must be transferred through the insect's mouthparts to the digestive tract or through penetration of the exoskeleton to the internal tissues and dsRNAs should be able to induce RNAi-response.

The basic outline for the development of an RNAi-based strategy to control insect pests by transgenic plants involves the following steps [10,16,17]: (1) selection of sequences of the targeted pests; (2) testing of selected dsRNAs in larval feeding assays with respect to toxicity/lethality; and (3) construction of RNA hairpin constructs that correspond to promising targets and generation of transgenic plants.

Although a wide range of successful RNAi experiments were published, an important variability of the RNAi success-among different insect orders-was a common observation in most of them [18]. Recently, several studies were focused on the causes of RNAi variability among different insect orders [19-21]. In general, beetles (Coleoptera) and cockroaches (Blattaria) are very sensitive to RNAi that is administered by injection or feeding; locusts (Orthoptera) are sensitive to RNAi by injection but are refractory to RNAi by feeding, while Lepidoptera are refractory to RNAi by both injection and feeding. Therefore, it is obvious that further research should focus on the thorough understanding of 
the process of RNAi in insects, especially in the Lepidopteran species. We should consider all factors that influence RNAi efficiency such as the gene target, administration method, and the uptake of dsRNA from the environment ("environmental RNAi") [19-21].

The Drosophila homolog of the mammalian retinoid $\mathrm{X}$ receptor known as ultraspiracle (USP), heterodimerizes with the ecdysone receptor $(\mathrm{EcR})$ in order to form a functional complex that in presence of the steroid molting hormone ecdysone activates and/or represses the expression of ecdysone responsive genes [22]. To interfere with this heterodimer, many insecticides were designed to mimic the action of the two major insect growth hormones, that is, the steroidal 20-hydroxyecdysone (20E) and the sesquiterpenoid juvenile hormone $(\mathrm{JH})$ [23]. Progress in EcR research has shown that the ligand-binding pocket of EcR is highly flexible and adaptable. This property of EcR permits the development of receptor systems for practical applications in medicine and agriculture [24]. Because of the tremendous physiological and molecular effects of $E c R$ and USP in the developmental processes of insects, both genes have attracted great attention in RNAi research as potential targets in the development of RNAi-based insecticides. Targeting these genes caused extended lethality and developmental malformations to many insects like in the Lepidopterans Hyblaea puera Cramer (Lepidoptera: Hyblaeidae) [25] and Spodoptera exigua [26], in the grain Aphid (Sitobion avenae F.) [27], in the Coleopteron Leptinotarsa decemlineata [28,29], in honey bees [30], in the cockroach Diploptera puncata, etc. [31]. Therefore, major concerns have emerged considering the RNAi efficiency in the Lepidopteran order [18] questioning whether this technology is indeed useful in the development of RNAi-based insecticides with respect to this insect order.

Previously we have demonstrated significant variability of RNAi in the Lepidopteran pest of corn, Sesamia nonagrioides. Keeping the factor gene target constant, our results showed a completely different pattern of RNAi effects with respect to parameters such as delivery methodology (injection, bacterial, baculovirus-mediated), administration time, dsRNA length, and gene coverage [32]. In this study we are demonstrating the phenotypic effects of silencing the ecdysone receptor $(E c R)$ and ultraspiracle (USP) genes in the moth S. nonagrioides and we discuss the possibility of an RNAi-based pest control strategy for this insect species.

\section{Materials and Methods}

\subsection{Insect Rearing and Staging of Larvae}

Insects were obtained from an established laboratory colony of S. nonagrioides, maintained at $25 \pm 1{ }^{\circ} \mathrm{C}, 55 \pm 5 \%$ relative humidity $(\mathrm{RH})$ and reared on an artificial diet [32] under long day (LD) conditions (16:8, light:dark). Larvae reared under LD conditions completed their larval life in 6 instars. The age of analyzed larvae within each instar was measured in days after the preceding ecdysis, in respect to physiological markers such as body mass and head capsule width. Nomenclature of stages follows the pattern of designation of the instar followed by the day of the stage (e.g., L5d2 denotes larvae of the 5th instar, 2 days after ecdysis). Larvae were observed daily for molting. To obtain synchronously growing animals, newly molted larvae were daily removed from the colony during the 6th-8th hour of photophase. The selected larvae had mean weight and mean head capsule width as follows: $101.3 \mathrm{mg}$ and $1.74 \mathrm{~mm}$ (L5d0); $160.4 \mathrm{mg}$ and $2.32 \mathrm{~mm}$ (L6d0). At the 9th day of the last instar, larvae transformed into prepupae (L6d9) and initiated metamorphosis.

\subsection{RNA Isolation, $c D N A$ Synthesis $\mathcal{E}$ Sequencing}

Total RNA was isolated from the whole body (RT-PCR assays), fat-body, or epidermal tissues of insects using TRIzol reagent (Sigma-Aldrich, Burlington, MA, USA) according to the supplier's instructions and stored at $-80^{\circ} \mathrm{C}$. The RNA concentration was measured using Beckman DU 640 Spectrophotometer (Beckman Instruments Inc., Fullerton, CA, USA). The isolated RNA was treated with the RNase-free DNAse I (Promega, Madison, WI, USA) and $1.5 \mu \mathrm{g}$ was used as template in first strand cDNA synthesis. The cDNAs 
were synthesized by priming with the universal primer Oligodt (Table S1), using the Superscript $^{\mathrm{TM}}$ II RNase H-Reverse Transcriptase (Invitrogen, Carlsbad, CA, USA). For ecdysone receptor partial S. nonagrioides $(S n E c R$ ) gene, degenerate primers (SnEcRDegF, SnEcRDegR, Table S1) were synthesized according to the nucleotide and amino acid sequences of various Lepidopteran EcR cDNAs (Spodoptera littoralis (HM445734), Spodoptera exigua (EU426551), Plodia interpunctella (AY489269), and Spodoptera litura (EU180021)) using the NCBI-BLAST2 algorithm (http:/ / expasy.org/tools/blast/, accessed on 24 December 2020). The cDNA sequences were aligned using the CLUSTALX (http://www.clustal. org, accessed on 24 December 2020) bioinformatics software and degenerate primers were designed on their highly homologous regions. Similarly, for ultraspiracle partial $S$. nonagrioides (SnUSP) gene, degenerate primers (SnUSPDegF, SnUSPDegR, Table S1) were designed according to the nucleotide and amino acid sequences of various Lepidopteran USP cDNAs (Plutella xylostella (XM_011559963), Helicoverpa armigera (EU526832), Spodoptera exigua (EU642475), and Spodoptera littoralis (HM445735)). The amount of cDNA derived from $200 \mathrm{ng}$ of total RNA isolated from epidermal (SnEcR) and fat body (SnUSP) tissues was used as template along with $200 \mu \mathrm{M}$ of each dNTP, 20 pmol of each primer, $1 \mathrm{U}$ of DNA polymerase (DyNAzyme ${ }^{\mathrm{TM}}$ EXT DNA Polymerase, Finnzymes Inc., Espoo, Southern Finland, Finland) in a $50 \mu \mathrm{L}$ reaction volume. Amplification was achieved in a Peltier thermal cycler (Model PTC-200, M.J. Research, Waltham, USA). After an initial denaturation step at $94^{\circ} \mathrm{C}$ for $2 \mathrm{~min}, 35$ cycles were run at $94{ }^{\circ} \mathrm{C}$ for $30 \mathrm{~s}, 56{ }^{\circ} \mathrm{C}$ for $30 \mathrm{~s}$, and $72{ }^{\circ} \mathrm{C}$ for $60 \mathrm{~s}$. The PCR products were gel extracted using a commercial kit (NucleoSpin ${ }^{\circledR}$ Extract II, Macherey-Nagel Inc., Allentown, PA, USA), T-A cloned into the pGEM-T Easy vector, (Promega, Madison, WI, USA) and sequenced using the T7 and SP6 primers. Partial cDNAs of $S n E c R$ and SnUSP genes were annotated in GenBank using the accession numbers JN572102 and JN704569 respectively. These partial cDNAs were both corresponding to the translated regions of $S n E c R$ and $S n U S P$ genes.

\subsection{Quantitative RT-PCR Analysis}

For quantitative RT-PCR analysis of SnEcR (GenBank: JN572102) and SnUSP (GenBank: JN704569) mRNA levels we used the primer sets SnEcRRTF/SnEcRR and SnUSPConF/SnUSPConR respectively (Table S1). As control, part of the coding region of $S$. nonagrioides b-tubulin gene (GenBank: DQ147771) was amplified by using the primer set TubF/TubR (Table S1). We have used b-tubulin as a control for quantitative RT-PCR analyses since we have already proven that the $S$. nonagrioides b-tubulin mRNA was consistent in different treatments and relative to (1) the nucleic acid concentration (using OD at $260 \mathrm{~nm}$ ) and (2) the quantity of rRNA bands present in agarose gels [32-38]. Incorporation of the fluorescent dye SYBR Green Brilliant (Stratagene, La Jolla, CA, USA) into double-stranded PCR products was used to determine the mRNA copy number of SnEcR and SnUSP. Standard plasmids were constructed by inserting a fragment from the coding region of $S n E c R$ and SnUSP (using the primer sets SnEcRRTF/SnEcRR and SnUSPConF/SnUSPConR respectively, Table S1) or S. nonagrioides b-tubulin (using the primer set TubF/TubR, Table S1) into pGEM T-easy vector (Promega, Madison, WI, USA). These plasmids were used as template DNA to produce standard curves. Each sample was analyzed in three technical triplicates and means were calculated. The quantity of mRNA levels was normalized with those of $b$-tubulin. Statistical analyses were performed using Student's $t$-Test and significant differences $(p<0.05)$ are indicated.

\subsection{Hemolymph dsEcR 427 Administration}

\subsection{1. dsRNA Quantity/Control Treatments}

For all experiments we used $4 \mu \mathrm{g}$ of the in vitro synthesized dsRNAs. For control injections we selected an in vitro synthesized dsRNA produced by the multiple cloning site of L4440 vector (Addgene, Cambridge, MA, USA), flanked by the T7 promoter sequences. To our knowledge, GFP-based or $\mathrm{ddH}_{2} \mathrm{O}$, which we had previously used as controls in RNAi experiments, resulted in the same effects in terms of semiquantitative/quantitative 
RT-PCR or phenotypic analysis when compared with these of the L4440's multiple cloning site [32,39]. The probe for RNA synthesis was isolated from L4440's multiple cloning site of $\sim 250 \mathrm{bp}$, by amplifying with the universal T7 primer (T7RNApOLPROM, Table S1). The amplified fragment flanked by the T7 promoter sequences was used as a template for dsRNA synthesis; T7 RNA polymerase (Thermo Fisher Scientific, Waltham, MA, USA) was allowed to run-off overnight at $37^{\circ} \mathrm{C}$. DNA was removed by DNase treatment (Promega, Madison, WI, USA). The dsRNA was then phenol/chloroform extracted, alcohol precipitated overnight, and quantified.

\subsubsection{Targeting $\mathrm{SnEcR}_{427}$}

Total RNA was isolated from the epidermal tissues of 6th instar larvae and transcribed into complementary DNA. Using SnEcRF/SnEcRR primer set the resulting 427 bp fragment was purified and cloned into the pGEM-T Easy vector (Promega, Madison, WI, USA) and following NotI digestion (New England Biolabs, Ipswich. MA, USA) was sub-cloned into the silencing L4440 (Addgene) vector. DH5 $\alpha^{\mathrm{TM}}$ competent cells (Thermo Fisher Scientific, Waltham, MA, USA) were transformed with the L4440:SnEcR 427 plasmid. Plasmid DNA from bacteria transformed with the L4440:SnEcR 427 was isolated and subjected in PCR reactions with the T7 universal primer T7RNApolProm (Table S1). This reaction resulted in the $S_{n E c} R_{427}$ fragment flanked by the sequences of the T7 promoter. The fragment was then purified (NucleoSpin ${ }^{\circledR}$ Extract II, Macherey-Nagel Inc., Allentown, PA, USA) and used as template in transcription reactions for the formation of the dsEcR ${ }_{427}$ using T7 RNA polymerase (Thermo Fisher Scientific, Waltham, MA, USA). DNA was removed by DNase treatment (RNase-free DNAse I, Promega, Madison, WI, USA) and the remaining dsRNA was phenol/chloroform extracted, alcohol precipitated, and quantified. Three trials of 30, 35 , and 35 S. nonagrioides 5th instar larvae each (total $n=100$ ) and 3 trials of 36,33 , and 31 S. nonagrioides prepupae each (total $n=100$ ) were performed by injecting $50 \mu \mathrm{L}$ of $4 \mu \mathrm{g}$ of the in vitro synthesized $\mathrm{dsEcR}_{427}$ using conventional $1 \mathrm{~mL}$ insulin syringes. For control injections same amount of $S$. nonagrioides 5 th instar larvae and prepupae were injected with $4 \mu \mathrm{g}$ of the in vitro synthesized dsRNAs transcribed by the multiple cloning site of the L4440 vector (Addgene, Cambridge, MA, USA). For RT-PCR analyses, we randomly selected 15 insects of each treatment and replicate, 3 days post injection. These were analyzed as individuals and subjected to semi-quantitative RT-PCR analyses in order to compare their $S n E c R$ mRNA levels. Samples with detectable $S n E c R$ mRNA down-regulation levels were further analyzed by quantitative real-time RT-PCR analyses.

\subsubsection{Bacterial Administration of dsEcR 427}

For control treatments, we transformed bacteria with the empty L4440 vector. This vector produces a range of unspecific dsRNA molecules from its multiple cloning site which is surrounded by the T7 promoter sequences [15,32]. The empty L4440 vector resulted in the same effects, in terms of semiquantitative/quantitative RT-PCR or phenotypic analysis, when compared with these of GFP-based constructs [32,39]. HT115 (DE3) competent cells lacking RNase III were prepared using standard $\mathrm{CaCl}_{2}$ methodology and were transformed with the L4440::SnEcR 427 plasmid. Single colonies of HT115/L4440::SnEcR 427 were cultured in $\mathrm{LB}$ at $37^{\circ} \mathrm{C}$ with shaking at $220 \mathrm{rpm}$ overnight. The culture was diluted 50 -fold in $100 \mathrm{~mL}$ LB supplemented with $100 \mu \mathrm{g} / \mathrm{mL}$ ampicillin (Sigma-Aldrich, Burlington, MA, USA) plus $15 \mu \mathrm{g} / \mathrm{mL}$ tetracycline (Sigma-Aldrich, Burlington, MA, USA) and cultured at $37{ }^{\circ} \mathrm{C}$ to $\mathrm{OD}_{600}=0.5$. Synthesis of T7 polymerase was induced with $0.4 \mathrm{mM} \mathrm{IPTG}$ and the bacteria were incubated with shaking for an additional $4 \mathrm{~h}$ at $37^{\circ} \mathrm{C}$. For feeding experiments, bacteria were centrifuged at $5000 \times g$ for $10 \mathrm{~min}$ and re-suspended in $0.5 \mathrm{~mL}$ of $\mathrm{ddH}_{2} \mathrm{O}$. In order to confirm efficient dsRNA expression, total RNA from the bacterial cells was isolated using TRIzol ${ }^{\circledR}$ reagent (Sigma-Aldrich, Burlington, MA, USA) according to the supplier's instructions. The RNA pellets were dissolved in $20 \mu \mathrm{L}$ of $\mathrm{ddH}_{2} \mathrm{O}$. In order to remove ssRNAs from the RNA samples $1 \mu \mathrm{g}$ RNase-A (Ribonuclease-A from bovine pancreas, Sigma -Aldrich, Burlington, MA, USA) and $\mathrm{NaCl}$ to $0.3 \mathrm{M}$ was added (RNase-A 
in high salinity buffers selectively digests ssRNAs leaving undigested the dsRNAs; [40] and incubated for $10 \mathrm{~min}$ at $37^{\circ} \mathrm{C}$. The length and the quality of the produced dsRNAs were confirmed by electrophoresis on $1 \%$ agarose gel. After confirmation of dsRNA synthesis, feeding bioassays were performed. One hundred $\mathrm{ml}$ of the IPTG induced cultures was centrifuged and pellets re-suspended in $0.5 \mathrm{~mL}$ of $\mathrm{ddH}_{2} \mathrm{O}$. The artificial diet was cut into different sizes of pellets depending on the instar and the number of feeding larvae. For each 100 S. nonagrioides neonates or 1 st or 2 nd instar larvae, a $10 \times 10 \times 10 \mathrm{~mm}^{3}$ pellet was used on which $100 \mu \mathrm{L}$ of fresh IPTG induced bacteria were applied every $12 \mathrm{~h}$. For each 100 3rd or 4th instar larvae, $200 \mu \mathrm{L}$ of fresh IPTG induced bacteria were applied on a $20 \times 20 \times 20 \mathrm{~mm}^{3}$ pellet, while for each 505 th or 6 th instar larvae $300 \mu \mathrm{L}$ of fresh IPTG induced bacteria were applied every $12 \mathrm{~h}$ on a $30 \times 30 \times 30 \mathrm{~mm}^{3}$ pellet. The pellets were replaced every 3 days, depending on the remaining undigested material. To perform bioassays, three trials of a total 100 insects each (total $n=300$ ) were used to assess the developmental impact of a potential SnEcR knock-down. As control IPTG induced HT115 bacteria transformed with the empty L4440 vector were used in additional three trials of a total 100 insects each (total $n=300$ ).

\subsubsection{Hemolymph dsUSP 689 Administration Using Bacterial dsRNA Extracts}

Total RNA was isolated from fat body tissues of 6th instar larvae and transcribed into cDNA. The cDNA was used in PCR reactions with the SnUSPConF/SnUSPConR primers (Table S1). The resulting $689 \mathrm{bp}$ fragment was purified and cloned into the pGEM-T Easy vector (Promega, Madison, WI, USA) and after digestion with XhoI and NcoI (New England Biolabs, Ipswich. MA, USA), was sub-cloned into the silencing L4440 vector (Addgene, Cambridge, MA, USA). The L4440:USP 689 plasmid was transformed into the HT115 bacteria and synthesis of dsUSP 689 was induced by IPTG. Total RNA from induced bacteria was isolated and analyzed on agarose gel to confirm dsRNA synthesis as it was described in the previous paragraphs. After the quantification of the dsRNA, the amount corresponding to total RNA isolated from a $5 \mathrm{~mL}$ liquid culture at $\mathrm{OD}_{600} \sim 1.0(5474.52 \pm 832.5 \mathrm{ng}$ estimated and normalized against the size of dsJHER 1276 as will be described below) was diluted in $50 \mu \mathrm{L} \mathrm{ddH} \mathrm{H}_{2} \mathrm{O}$ and then injected to L6d6 S. nonagrioides larvae using conventional $1 \mathrm{~mL}$ insulin syringes in 3 trials of 32, 35, and 33 insects (total $n=100$ ). For control injections same number of $S$. nonagrioides L6d6 larvae were injected with $3 \mu \mathrm{g}$ of total RNA isolated from a $5 \mathrm{~mL}$ liquid culture at $\mathrm{OD}_{600} \sim 1.0$ of IPTG-induced L4440 (empty) transformed HT115 bacteria.

\section{Results}

\subsection{Optimization of Bacterial dsRNA Synthesis}

Using a $1276 \mathrm{bp}$ part of the $S$. nonagrioides juvenile hormone esterase related gene $\left(S n J H E R_{1276}\right)$ (EU178813), we standardized an accurate and efficient protocol for dsRNA expression and dsRNA quantification in the HT115 (DE3) bacteria. The protocol involved the following steps: (1) overnight culture of transformed HT115 (DE3) bacteria in $5 \mathrm{~mL}$ of liquid LB containing $100 \mu \mathrm{g} / \mathrm{mL}$ ampicillin and $15 \mu \mathrm{g} / \mathrm{mL}$ tetracycline at $37^{\circ} \mathrm{C}$ with shaking at $220 \mathrm{rpm}$; (2) after 50-fold dilution, incubation of culture in LB medium at $37^{\circ} \mathrm{C}$ with shaking at $220 \mathrm{rpm}$ until to optical density at $600 \mathrm{~nm}\left(\mathrm{OD}_{600}\right)$ reaches $0.5 ;(3)$ addition of $0.4 \mathrm{mM}$ IPTG for induction of T7 polymerase and incubation for an additional $4 \mathrm{~h}$ at $37^{\circ} \mathrm{C}$ up to $\mathrm{OD}_{600}$ reaches 1.0 ; (4) harvest of bacteria after centrifugation at 13,000 rpm for 5 min; (4) isolation of total RNA using TRIzol ${ }^{\circledR}$ reagent followed by RNase protection assays; (5) analysis and quantification of dsRNA synthesis by Nanodrop spectrophotometer and agarose gel electrophoresis.

RNase-A dsRNA protection assays were performed as previously described [15,32]. In order to remove ssRNAs from the bacterial extracts, $1 \mu \mathrm{g}$ of RNase-A was added in the presence of high salt $(0.3 \mathrm{M} \mathrm{NaCl})$ and incubated for $10 \mathrm{~min}$ at $37^{\circ} \mathrm{C}$. The length and the quality of the produced dsRNAs were confirmed by electrophoresis in a $1 \% \mathrm{w} / \mathrm{v}$ agarose gel (Figure 1). Using the above mentioned methodology it was observed that $1.5 \mathrm{~mL}$ of 
the HT115-induced E.coli strain at $\mathrm{OD}_{600}$ of 1.0 produces $822 \pm 125 \mathrm{ng}$ ( $n=3$ replicates) of SnJHER dsRNA after RNase-A treatment. For daily routine experiments TRIzol ${ }^{\circledR}$ RNA extracts (without RNase treatment) were constantly analyzed in order to confirm dsRNA synthesis (Figure S1).

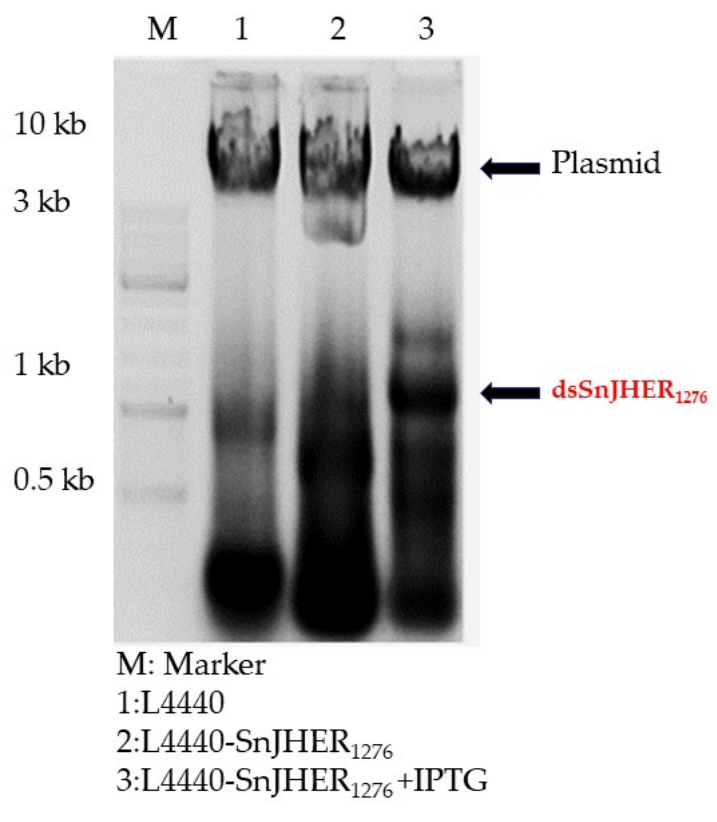

(A)

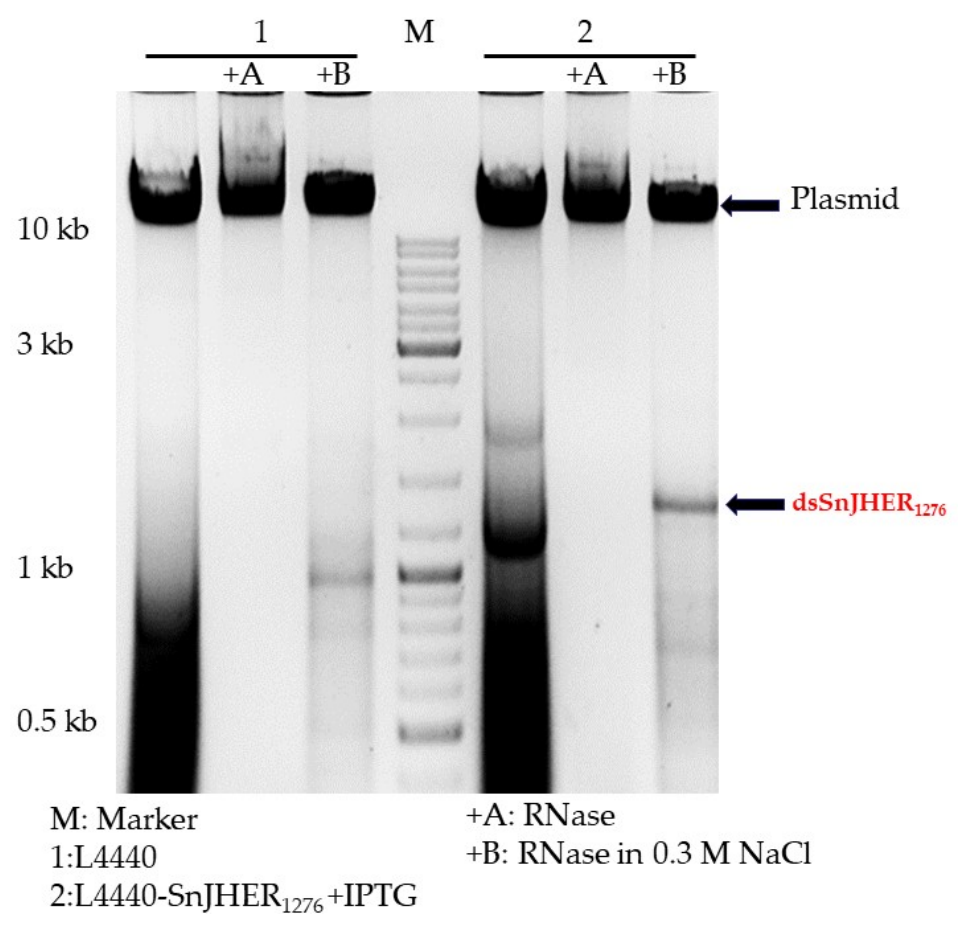

(B)

Figure 1. Production of SnJHER 1276 dsRNAs in HT115 cells. (A). Total RNA isolated from L4440 or L4440-SnJHER ${ }_{1276}{ }^{-}$ transformed HT115 bacteria was analyzed in 1\% w/v agarose gel. 1, 2: Non-induced, 3: IPTG induced bacteria. (B). IPTG induced RNA extracts were treated with $1 \mu \mathrm{g}$ RNase A or $1 \mu \mathrm{g}$ RNase A in the presence of $0.3 \mathrm{M} \mathrm{NaCl}$. (M). Molecular marker. Production of dsSHER 1276 is indicated. Unspecific dsRNA products of the empty L4440 plasmid can be observed in $1 \mathrm{~kb}$.

\subsection{Functional Analysis of S. nonagrioides Ecdysone Receptor Gene Using Different RNAi Delivery Methods}

The partial cDNA sequence of $S$. nonagrioides ecdysone receptor gene $(S n E c R)$ has a length of $1075 \mathrm{bp}$ (NCBI database number JN572102). Using bioinformatic analysis it was revealed that $S n E c R$ had sequence identity at the nucleotide level of $89 \%$ with the ecdysone receptor of Helicoverpa armigera (accession number: EU526831). Additionally, $S n E c R$ exhibited all conserved domains of EcR proteins (partial sequence of DNA-binding domain and major part of ligand-binding domain) (data not shown). SnEcR was grouped together with the EcR proteins of other lepidopterans and localized between the A- and Bisoform branches (no isoform-specific sequences are present in the partial $S n E c R$ sequence) (data not shown). In our previous RNAi experiments (targeting the S. nonagrioides SnJHER gene), RNAi-specific phenotypes were observed only when insects were injected with gene specific dsRNAs at their prepupal stages [32]. Although gene silencing was observed when S. nonagrioides insects were injected at their larval stages as well, a knock-down specific phenotype was never developed [32]. Here we observed a very similar phenomenon. When 3 replicates of a total $n=100$ of S. nonagrioides 5 th instar larvae (three trials of 30, 35 , and 355 th instar larvae, see M\&M for details) were injected with $4 \mu \mathrm{g}$ of dsEcR $\mathrm{R}_{427}$ we observed no changes in their mortality levels. Moreover, all insects were normally developed even if randomly selected $\mathrm{dsEcR}_{427}$-injected insects presented lower $S n E c R$ mRNA levels (Figure 2). 


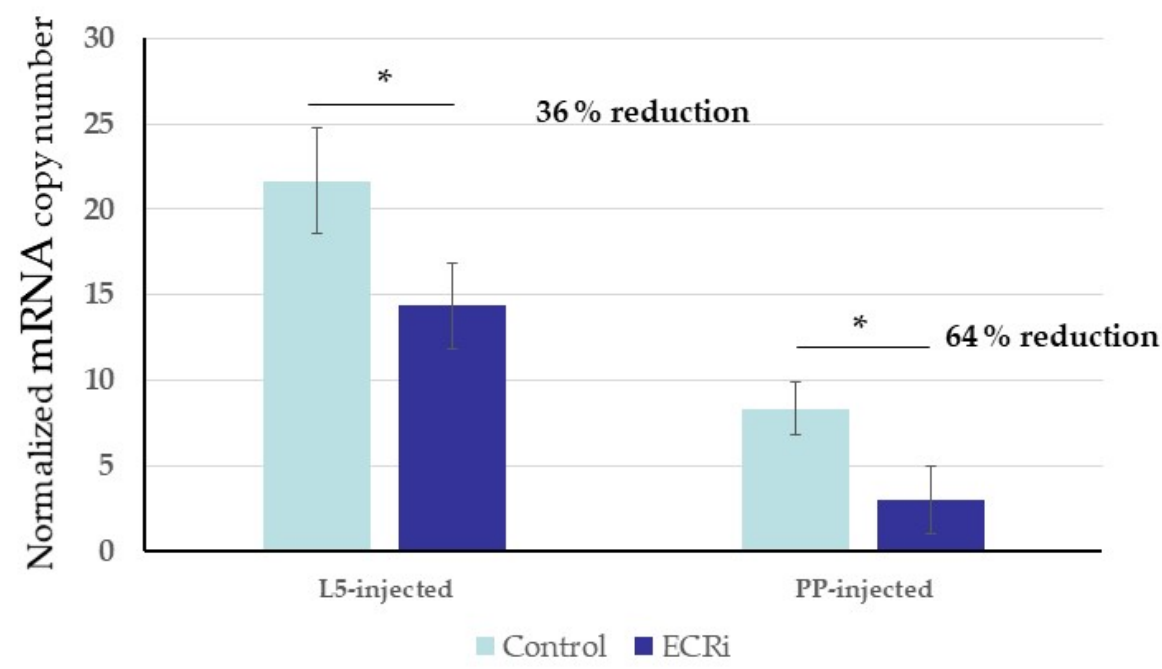

Figure 2. Real time RT-PCR analysis of $S n E c R$ mRNA levels normalized against the $S n b$-Tub in a pool of 15 randomly selected 5th instar larvae (L5) and prepupae (PP) injected with either the dsEcR $R_{427}$ (EcRi) or control (dsL4440) three days post injection. Data represent \pm SD of 3 biological replicates of a pool of 15 insects each $\times 3$ technical replicates. Statistical differences were performed for EcRi against control treatments using Student's $t$-Test $\left({ }^{*}<0.05\right)$.

In contrast, when 3 replicates of a total $n=100$ of $S$. nonagrioides prepupae were injected with $4 \mu \mathrm{g}$ of dsEcR 427 , an average percentage of $16 \pm 1.5 \%$ ( 3 biological replicates of 36,33 , and 31 S. nonagrioides prepupae each) of them died as larval-pupal intermediates (Figure 3B). These insects where unable to pupate normally and exhibited low levels of $S n E c R$ mRNA expression compared with the control insects which were injected with dsRNAs derived from the $\sim 240 \mathrm{bp}$ cloning region of the L4440 vector (Figure 2). The remaining surviving $84 \pm 1.5 \%$ of the injected prepupae successfully transitioned to the next (adult) stage. However, only an average of a total of $72 \pm 17 \%$ of the surviving dsEcR $R_{427}$ injected animals developed into normal adults while $28 \pm 17 \%$ developed into adults who were unable to successfully emerge because their heads remained fused with the pupal tissues and/or into adults with curly wings (Figure 3C).

In addition to hemolymph injections we tested the effects of a continuous administration of bacteria producing the dsEcR 427 molecules throughout larval development (L1 to L5 larval instars). HT115/L4440::dsEcR 427 induced bacteria were applied to $S$. nonagrioides' artificial diet. Control insects were fed with HT115/L4440 induced bacteria. Experiments were performed in three trials of a total 100 insects each (total $n=300$ ). Although real-time RT-PCR analyses showed a non-significant ( 3 biological replicates of a pool of 15 insects each $\times 3$ technical replicates, Student's t-Test)(data not shown) EcRi knockdown effect, we have not observed any significant phenotype or significantly increased mortality levels in these insects. A minor phenotype however was observed at the end of the 5th instar in a small number of insects $(9 \pm 2.7 \%)$ which presented thickness and transparency at the larval intersegmental membranes (data not shown) that evolved into (healing) melanization lines surrounding those previously weakened areas after the feeding period (Figure 3D). It was also observed that $5.3 \pm 2.5 \%$ of the total HT115/L4440::dsEcR 427 fed S. nonagrioides larvae presented a phenotype that could be described as a darkened haemocoel enclosing their digestive system. These abnormalities were observed at the 5 th instar after continuous feeding with $\mathrm{dsEcR}_{427}$ during 5 successive larval stages (Figure 3E). Despite the previous observation it was revealed that the HT115/L4440 controls also presented the aforementioned phenotype at a percentage of $5 \pm 3.6 \%$ (Figure 3E). This phenotype was likely caused by a general toxicity effect from feeding E. coli and therefore was not considered as specific for RNAi of $S n E c R$. 
A.
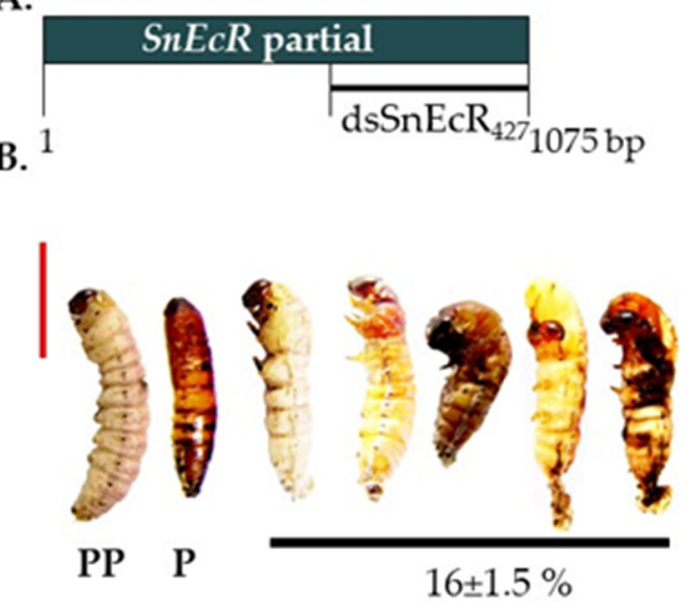

C.

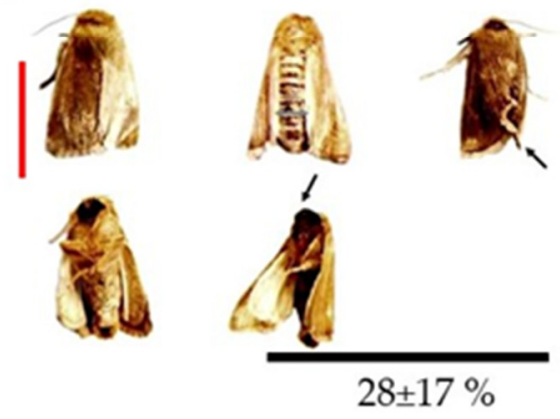

D.
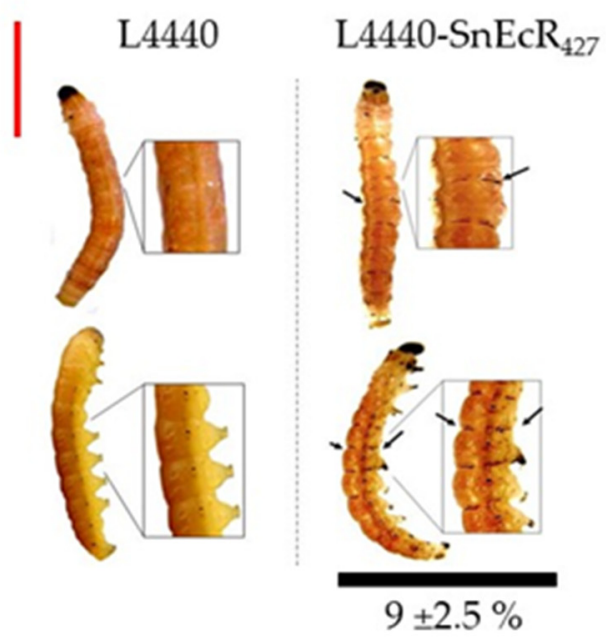

E.

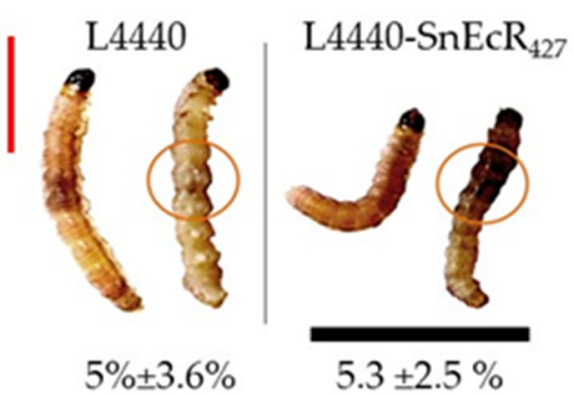

Figure 3. RNAi of EcR in S. nonagrioides. (A). Schematic representation of the partial cDNA sequence of the S. nonagrioides ecdysone receptor $(S n E c R)$ gene. The bar below the sequence indicates the fragment used for the synthesis of the dsEcR 427 . (B). Malformations of larval-pupal metamorphosis in EcRi S. nonagrioides insects injected at their prepupal stage. PP: Normal prepupae, P: Normal pupae. (C). Malformations in S. nonagrioides adults that were injected with $4 \mu \mathrm{g}$ of dsEcR 427 as prepupae and underwent normal pupation (as shown in (A)). Arrows indicate wing malformations and fused adult heads with pupal tissues. (D). Malformations of S. nonagrioides L5 larvae fed with the HT115/L4440:SnEcR 427 bacteria throughout their entire larval life. (E). Common developmental abnormalities between S. nonagrioides L5 larvae fed with the HT115/L4440::dsEcR 427 and HT115/L4440 bacteria throughout their entire larval life. Red bar indicates length equal to $1 \mathrm{~cm}$.

\subsection{Functional Analysis of S. nonagrioides USP Gene}

The isolated partial cDNA sequence of $S$. nonagrioides ultraspiracle gene (SnUSP) was 800 bp long (NCBI database number JN704569). Using bioinformatic analysis it was revealed that SnUSP had sequence identity at the nucleotide level of $87 \%$ with the USP gene of Helicoverpa armigera (accession number: EU526832). Additionally, SnUSP exhibited all conserved domains characteristic of USP proteins (DNA-binding domain and partial and-binding domain) (data not shown). For SnUSP it was decided to inject RNA extracts from induced dsRNA-expressing HT115 bacteria as an alternative technique which was never reported before. After the quantification of the dsRNA, the amount corresponding to total RNA isolated from a $5 \mathrm{~mL}$ liquid culture at $\mathrm{OD}_{600}$ of 1 (5474.52 $\pm 832.5 \mathrm{ng}$ estimated and normalized against the size of dsJHER ${ }_{1276}$ ) was injected into each of a total of $n=100$ (3 trials of 32, 35, and 33 L6d6 larvae). As control, insects were injected with total RNA isolated from induced L4440 transformed HT115 bacteria $n=100$ (3 trials of 32, 35, and 33 L6d6 larvae). At day 3 post injection insects were expected to molt into the prepupal stage. For that reason, it was decided to analyze transcript levels of SnUSP one day earlier (day 2 post-injection). Using extracts from randomly selected L6d8 insects for semi-quantitative RT-PCR analysis, it was found that insects injected with the L4440:USP 689 exhibited low levels of the SnUSP mRNA compared to the injected L4440 ones (Figure 4B). On the other hand, only $34.91 \pm 10.24 \%$ of the total 
L4440:USP689-injected insects were able to pupate 6 days post injection while a $95.03 \pm 1.60 \%$ pupation was observed in the total L4440-injected ones ( $p<0.05$, Student's $t$-Test). The 100\% pupation end-point was achieved 2 days after the expected for the L4440-injected insects while in this day only a $42.83 \pm 10.44 \%$ of the L4440:USP689-injected ones was able to pupate normally ( $p<0.05$, Student's $t$-Test). The 100\% pupation end-point for the L4440:USP 689 -injected insects was achieved 12 days after the expected day, a delay that could be considered as a canonical phenotype related to USP silencing (Figure 4C). Moreover, no mortality rates were recorded despite the delay in the developmental procedure.

A.

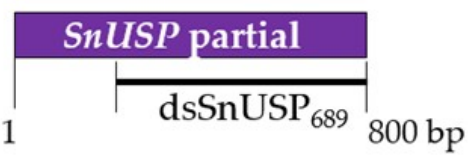

C.

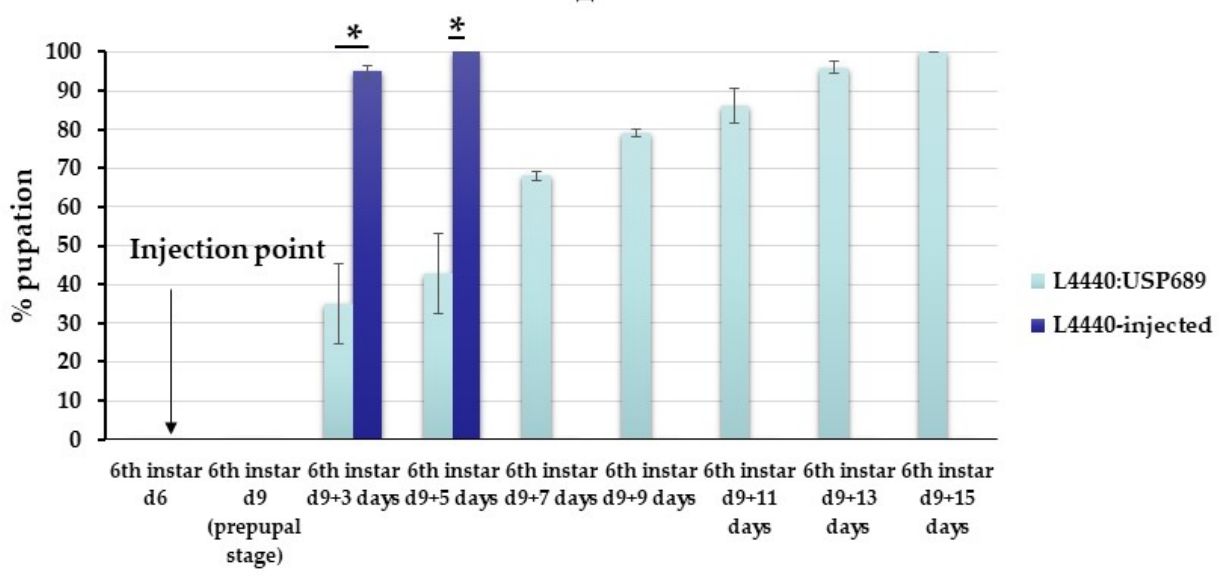

Figure 4. RNAi of USP by hemolymph injection in S. nonagrioides. (A). Schematic representation of the partial cDNA sequence of the $S$. nonagrioides ultraspiracle $(S n U S P)$ gene. The bar above the sequence indicates the fragment used for the synthesis of the dsUSP 689 . (B). Real time RT-PCR analysis of SnUSP mRNA levels normalized against the Snb-Tub in a pool of 15 randomly selected L6d8 larvae two days post injection. Data represent \pm SD of 3 biological replicates of a pool of 15 insects each $\times 3$ technical replicates. Statistical differences are shown for USPi against control treatments using Student's t-Test $\left({ }^{*}<0.05\right)$. (C). Pupation rate of L4440 versus L4440:USP 689 -injected animals. Statistical differences of pupation delay among L4440-injected versus L4440:USP 689 injected are shown with asterisks ( $p<0.05$, Student's $t$-Test).

\section{Discussion}

While the concept of RNAi for insect pest control has been proven in seminal proof-ofconcept studies $[10,11]$, the variability of the efficiency of this approach has also become clear during the following decade [41,42]. Analysis of a database of RNAi experiments in Lepidoptera did not result in clear recommendations for the strategy of dsRNA delivery that would work best in lepidopteran insects [18]. It therefore appears that for each insect separately the best strategy needs to be experimentally determined.

In our previous work [32], different approaches were tested to knock down the juvenile hormone-related esterase (JHER) gene in S. nonagrioides. It was demonstrated that injection of dsRNA in larvae can result in efficient gene silencing concomitant with phenotypic effects, which was confirmed in this study, where other genes (EcR and USP) are targeted (Figures 2-4). By contrast, feeding of bacteria expressing dsRNA targeting JHER did not result in phenotypic effects despite the observation of gene silencing [32]. This is also confirmed in this study where only limited phenotypic effects were observed after feeding of bacteria expressing EcR dsRNA 
(Figure 3D); in addition, common phenotypes were observed in larvae that were fed with bacteria expressing the control dsRNA ((Figure 3E)). The absence of phenotypic effects was noted despite the observation of gene silencing: 36\% for dsSnEcR injected in larval stages, $64 \%$ for dsSnEcR injected in the prepupal stages, and $44.2 \%$ for dsSnUSP injected in the larval stages of $S$. nonagrioides (Figures 2 and 4).

In this study, delivery of dsRNA extracted from bacteria was also explored to test the knock-down of USP in S. nonagrioides. In this case the stage prior to pupation (L6d6) was targeted which has been reported to be more sensitive to administration of dsRNA [39]. Phenotypic effects (delay of pupation) were observed together with USP mRNA knockdown (Figure 4). This result is significant from the viewpoint that dsRNA production in bacteria is much cheaper than by in vitro synthesis using T7 RNA polymerase which is important when large amounts are needed for tests in fields $[43,44]$.

To achieve RNAi effects in a particular insect species, it is therefore necessary to try different approaches to achieve success. It can be noted that, despite the generally acknowledged difficulties in achieving RNAi in lepidopteran insects [18], transgenic cotton plants expressing dsRNAs targeting JH synthesis and transport in combination with $\mathrm{Bt}$ toxins are effective to control the cotton bollworm, Helicoverpa armigera $[45,46]$. Because dsRNA has a completely different mode of action than Bt toxins, co-incorporation of RNAi in transgenic plants ("pyramided approach") is expected to result in delay of insecticide resistance [17]. Thus, although RNAi by itself may not be robust enough to achieve significant phenotypic effects or (sub) lethality, it can effectively be combined with other insecticides in a synergistic manner. In another application, RNAi could also be used to knock down resistance genes against chemical insecticides, thus decreasing the effective dose and increasing safety [47].

Whether a similar approach (RNAi pyramided with Bt toxin in corn) can be used for control of $S$. nonagrioides or other lepidopteran corn pests remains to be explored in the future. The components of the ecdysone receptor complex, EcR and USP, have been popular targets for RNAi experiments in the past. In larvae, silencing of EcR or USP typically results in molting defects and disruption of metamorphosis. On the other hand, physiological processes in adults, such as reproduction, lipid metabolism, and behavior, can also be severely disturbed after inhibition of ecdysone signaling, and in the case of the pea aphid, transgenerational effects on the phenotype of the offspring were observed [48]. Thus, silencing of EcR/USP can represent a good strategy of pest control that will affect all stages of development of insect pests. Of importance is the observation that transgenic plants that target EcR by RNAi have been successful for the control of several pests: Leptinotarsa decemlineata by transgenic potato [49], Bemisia tabaci, Helicoverpa armigera and Spodoptera exigua by transgenic tobacco [50,51], and Nilaparvata lugens by transgenic rice [52].

The research presented here provides useful information: that targeting $S$. nonagrioides $E c R$ and USP genes by RNAi did not result in important developmental defects and mortalities that could be assessed positively in designing of an RNAi-based pesticide to combat this important pest of corn. RNAi technology is one of the most recent trends in the field of crop protection and conceptually approaches the "ideal" of the perfect pesticide: it targets only the intended pest and is predicted to have minimal impact on the non-target organisms (pollinators, parasitoids, predators, and vertebrates) [15,53-55]. Furthermore, it is biodegradable and therefore with minimal risk for human health and the environment [15,53-55]. The use of this technology to control Lepidopteran pests and more specifically $S$. nonagrioides needs a considerable improvement for the reasons mentioned previously. To our knowledge, new approaches must be adopted in order for RNAi to find application in managing populations of the Lepidopteran pests. Technologies that were proved to be efficient in modern medicine that involve RNAi, e.g., Virus Like Particles, Ribonucleoproteins, etc., must be investigated in RNAi-mediated pest control. These technologies are estimated to be able to overcome all obstacles that insect cells pose to RNAi and the future for the mass production of RNAi pesticides lies ahead [15,53-55]. 
Supplementary Materials: The following are available online at https: / www.mdpi.com/article/ $10.3390 /$ d13120677/s1, Figure S1. Production of SnJHER 1276, SnEcR $_{427}$ and SnUSP $_{689}$ dsRNAs in HT115 cells, Table S1: PCR primers used in this study.

Author Contributions: Conceptualization, D.K. and A.K.; methodology, D.K.; software, D.K.; validation, D.K., L.S. and A.K.; formal analysis, D.K.; investigation, D.K.; resources, D.K.; data curation, D.K.; writing — original draft preparation, D.K.; writing—review and editing, D.K.; visualization, D.K.; supervision, D.K.; project administration, D.K.; funding acquisition, D.K. All authors have read and agreed to the published version of the manuscript.

Funding: This research received no external funding.

Institutional Review Board Statement: Not applicable.

Informed Consent Statement: Not applicable.

Data Availability Statement: Data is contained within the article and supplementary material.

Acknowledgments: This research is implemented through IKY scholarships program and cofinanced by the European Union (European Social Fund-ESF) and Greek national funds through the action entitled "Reinforcement of Postdoctoral Researchers", in the framework of the Operational Programme "Human Resources Development Program, Education and Lifelong Learning" of the National Strategic Reference Framework (NSRF) 2014-2020.

Conflicts of Interest: The authors declare no conflict of interest.

\section{References}

1. Hannon, G.J. RNA Interference. Nature 2002, 418, 244-251. [CrossRef]

2. Wynant, N.; Santos, D.; Broeck, J.V. The Evolution of Animal Argonautes: Evidence for the Absence of Antiviral AGO Argonautes in Vertebrates. Sci. Rep. 2017, 7, 9230. [CrossRef] [PubMed]

3. Bartel, D.P. MicroRNAs: Target Recognition and Regulatory Functions. Cell 2009, 136, 215-233. [CrossRef] [PubMed]

4. Timmons, L.; Court, D.L.; Fire, A. Ingestion of Bacterially Expressed DsRNAs Can Produce Specific and Potent Genetic Interference in Caenorhabditis Elegans. Gene 2001, 263, 103-112. [CrossRef]

5. Tuschl, T.; Zamore, P.D.; Lehmann, R.; Bartel, D.P.; Sharp, P.A. Targeted MRNA Degradation by Double-Stranded RNA in Vitro. Genes Dev. 1999, 13, 3191-3197. [CrossRef]

6. Kennerdell, J.R.; Carthew, R.W. Heritable Gene Silencing in Drosophila Using Double-Stranded RNA. Nat. Biotechnol. 2000, 18, 896-898. [CrossRef]

7. Dzitoyeva, S.; Dimitrijevic, N.; Manev, H. Intra-Abdominal Injection of Double-Stranded RNA into Anesthetized Adult Drosophila Triggers RNA Interference in the Central Nervous System. Mol. Psychiatry 2001, 6, 665-670. [CrossRef] [PubMed]

8. Rajagopal, R.; Sivakumar, S.; Agrawal, N.; Malhotra, P.; Bhatnagar, R.K. Silencing of Midgut Aminopeptidase N of Spodoptera Litura by Double-Stranded RNA Establishes Its Role AsBacillus Thuringiensis Toxin Receptor. J. Biol. Chem. 2002, 277, 4684946851. [CrossRef]

9. Araujo, R.N.; Santos, A.; Pinto, F.S.; Gontijo, N.F.; Lehane, M.J.; Pereira, M.H. RNA Interference of the Salivary Gland Nitrophorin 2 in the Triatomine Bug Rhodnius Prolixus (Hemiptera: Reduviidae) by DsRNA Ingestion or Injection. Insect Biochem. Mol. Biol. 2006, 36, 683-693. [CrossRef]

10. Baum, J.A.; Bogaert, T.; Clinton, W.; Heck, G.R.; Feldmann, P.; Ilagan, O.; Johnson, S.; Plaetinck, G.; Munyikwa, T.; Pleau, M. Control of Coleopteran Insect Pests through RNA Interference. Nat. Biotechnol. 2007, 25, 1322-1326. [CrossRef]

11. Mao, Y.-B.; Cai, W.-J.; Wang, J.-W.; Hong, G.-J.; Tao, X.-Y.; Wang, L.-J.; Huang, Y.-P.; Chen, X.-Y. Silencing a Cotton Bollworm P450 Monooxygenase Gene by Plant-Mediated RNAi Impairs Larval Tolerance of Gossypol. Nat. Biotechnol. 2007, 25, 1307-1313. [CrossRef]

12. Baum, J.A.; Roberts, J.K. Progress towards RNAi-Mediated Insect Pest Management. Adv. Insect Physiol. 2014, 47, $249-295$.

13. Tian, H.; Peng, H.; Yao, Q.; Chen, H.; Xie, Q.; Tang, B.; Zhang, W. Developmental Control of a Lepidopteran Pest Spodoptera Exigua by Ingestion of Bacteria Expressing DsRNA of a Non-Midgut Gene. PLoS ONE 2009, 4, e6225. [CrossRef]

14. Li, X.; Zhang, M.; Zhang, H. RNA Interference of Four Genes in Adult Bactrocera Dorsalis by Feeding Their DsRNAs. PLoS ONE 2011, 6, e17788. [CrossRef] [PubMed]

15. Kourti, A.; Swevers, L.; Kontogiannatos, D. In Search of New Methodologies for Efficient Insect Pest Control: The RNAi "Movement". In Biological Control of Pest and Vector Insects; InTech Rijeka: Rijeka, Croatia, 2017.

16. Gordon, K.H.; Waterhouse, P.M. RNAi for Insect-Proof Plants. Nat. Biotechnol. 2007, 25, 1231-1232. [CrossRef] [PubMed]

17. Swevers, L.; Smagghe, G. Use of RNAi for Control of Insect Crop Pests. In Arthropod-Plant Interactions; Springer: Berlin/Heidelberg, Germany, 2012; pp. 177-197. 
18. Terenius, O.; Papanicolaou, A.; Garbutt, J.S.; Eleftherianos, I.; Huvenne, H.; Kanginakudru, S.; Albrechtsen, M.; An, C.; Aymeric, J.-L.; Barthel, A. RNA Interference in Lepidoptera: An Overview of Successful and Unsuccessful Studies and Implications for Experimental Design. J. Insect Physiol. 2011, 57, 231-245. [CrossRef]

19. Ivashuta, S.; Zhang, Y.; Wiggins, B.E.; Ramaseshadri, P.; Segers, G.C.; Johnson, S.; Meyer, S.E.; Kerstetter, R.A.; McNulty, B.C.; Bolognesi, R. Environmental RNAi in Herbivorous Insects. RNA 2015, 21, 840-850. [CrossRef]

20. Shukla, J.N.; Kalsi, M.; Sethi, A.; Narva, K.E.; Fishilevich, E.; Singh, S.; Mogilicherla, K.; Palli, S.R. Reduced Stability and Intracellular Transport of DsRNA Contribute to Poor RNAi Response in Lepidopteran Insects. RNA Biol. 2016, 13, 656-669. [CrossRef] [PubMed]

21. Wang, X.; Hou, Y.; Saha, T.T.; Pei, G.; Raikhel, A.S.; Zou, Z. Hormone and Receptor Interplay in the Regulation of Mosquito Lipid Metabolism. Proc. Natl. Acad. Sci. USA 2017, 114, E2709-E2718. [CrossRef] [PubMed]

22. Ghbeish, N.; Tsai, C.-C.; Schubiger, M.; Zhou, J.Y.; Evans, R.M.; McKeown, M. The Dual Role of Ultraspiracle, the Drosophila Retinoid X Receptor, in the Ecdysone Response. Proc. Natl. Acad. Sci. USA 2001, 98, 3867-3872. [CrossRef]

23. Dhadialla, T.S.; Carlson, G.R.; Le, D.P. New Insecticides with Ecdysteroidal and Juvenile Hormone Activity. Annu. Rev. Entomol. 1998, 43, 545-569. [CrossRef]

24. Palli, S.R.; Hormann, R.E.; Schlattner, U.; Lezzi, M. Ecdysteroid Receptors and Their Applications in Agriculture and Medicine. Vitam. Horm. 2005, 73, 59-100. [PubMed]

25. Kottaipalayam-Somasundaram, S.R.; Jacob, J.P.; Aiyar, B.; Merzendorfer, H.; Nambiar-Veetil, M. Chitin Metabolism as a Potential Target for RNAi-based Control of the Forestry Pest Hyblaea Puera Cramer (Lepidoptera: Hyblaeidae). Pest Manag. Sci. 2021, 78, 296-303. [CrossRef]

26. Zhang, Z.; Ma, Y.; Ma, X.; Hu, H.; Wang, D.; Song, X.; Ren, X.; Ma, Y. Combined Transcriptomic Analysis and RNA Interference Reveal the Effects of Methoxyfenozide on Ecdysone Signaling Pathway of Spodoptera Exigua. Int. J. Mol. Sci. 2021, 22, 9080. [CrossRef] [PubMed]

27. Yan, T.; Chen, H.; Sun, Y.; Yu, X.; Xia, L. RNA Interference of the Ecdysone Receptor Genes EcR and USP in Grain Aphid (Sitobion Avenae F.) Affects Its Survival and Fecundity upon Feeding on Wheat Plants. Int. J. Mol. Sci. 2016, 17, 2098. [CrossRef]

28. Xu, Q.-Y.; Deng, P.; Zhang, Q.; Li, A.; Fu, K.-Y.; Guo, W.-C.; Li, G.-Q. Ecdysone Receptor Isoforms Play Distinct Roles in Larval-Pupal-Adult Transition in Leptinotarsa Decemlineata. Insect Sci. 2020, 27, 487-499. [CrossRef]

29. Xu, Q.-Y.; Du, J.-L.; Mu, L.-L.; Guo, W.-C.; Li, G.-Q. Importance of Taiman in Larval-Pupal Transition in Leptinotarsa Decemlineata. Front. Physiol. 2019, 10, 724. [CrossRef] [PubMed]

30. Ament, S.A.; Wang, Y.; Chen, C.-C.; Blatti, C.A.; Hong, F.; Liang, Z.S.; Negre, N.; White, K.P.; Rodriguez-Zas, S.L.; Mizzen, C.A. The Transcription Factor Ultraspiracle Influences Honey Bee Social Behavior and Behavior-Related Gene Expression. PLoS Genet. 2012, 8, e1002596. [CrossRef] [PubMed]

31. Hult, E.F.; Huang, J.; Marchal, E.; Lam, J.; Tobe, S.S. RXR/USP and EcR Are Critical for the Regulation of Reproduction and the Control of JH Biosynthesis in Diploptera Punctata. J. Insect Physiol. 2015, 80, 48-60. [CrossRef]

32. Kontogiannatos, D.; Swevers, L.; Maenaka, K.; Park, E.Y.; Iatrou, K.; Kourti, A. Functional Characterization of a Juvenile Hormone Esterase Related Gene in the Moth Sesamia Nonagrioides through RNA Interference. PLoS ONE 2013, 8, e73834. [CrossRef]

33. Spiliotopoulos, A.; Gkouvitsas, T.; Fantinou, A.; Kourti, A. Expression of a CDNA Encoding a Member of the Hexamerin Storage Proteins from the Moth Sesamia Nonagrioides (Lef.) during Diapause. Comp. Biochem. Physiol. B Biochem. Mol. Biol. 2007, 148, 44-54. [CrossRef] [PubMed]

34. Gkouvitsas, T.; Kontogiannatos, D.; Kourti, A. Differential Expression of Two Small Hsps during Diapause in the Corn Stalk Borer Sesamia Nonagrioides (Lef.). J. Insect Physiol. 2008, 54, 1503-1510. [CrossRef] [PubMed]

35. Kontogiannatos, D.; Gkouvitsas, T.; Kourti, A. The Expression Patterns of the Clock Genes Period and Timeless Are Affected by Photoperiod in the Mediterranean Corn Stalk Borer, Sesamia Nonagrioides. Arch. Insect Biochem. Physiol. 2017, 94 , e21366. [CrossRef]

36. Kontogiannatos, D.; Swevers, L.; Kourti, A. Recent Gene Multiplication and Evolution of a Juvenile Hormone Esterase-Related Gene in a Lepidopteran Pest. Gene Rep. 2016, 4, 139-152. [CrossRef]

37. Gkouvitsas, T.; Kontogiannatos, D.; Kourti, A. Expression of the Hsp83 Gene in Response to Diapause and Thermal Stress in the Moth Sesamia Nonagrioides. Insect Mol. Biol. 2009, 18, 759-768. [CrossRef]

38. Gkouvitsas, T.; Kontogiannatos, D.; Kourti, A. Cognate Hsp70 Gene Is Induced during Deep Larval Diapause in the Moth Sesamia Nonagrioides. Insect Mol. Biol. 2009, 18, 253-264. [CrossRef]

39. Guo, E.; He, Q.; Liu, S.; Tian, L.; Sheng, Z.; Peng, Q.; Guan, J.; Shi, M.; Li, K.; Gilbert, L.I. MET Is Required for the Maximal Action of 20-Hydroxyecdysone during Bombyx Metamorphosis. PLoS ONE 2012, 7, e53256.

40. Molnár, A.; Csorba, T.; Lakatos, L.; Várallyay, É.; Lacomme, C.; Burgyán, J. Plant Virus-Derived Small Interfering RNAs Originate Predominantly from Highly Structured Single-Stranded Viral RNAs. J. Virol. 2005, 79, 7812-7818. [CrossRef] [PubMed]

41. Scott, J.G.; Michel, K.; Bartholomay, L.C.; Siegfried, B.D.; Hunter, W.B.; Smagghe, G.; Zhu, K.Y.; Douglas, A.E. Towards the Elements of Successful Insect RNAi. J. Insect Physiol. 2013, 59, 1212-1221. [CrossRef]

42. Joga, M.R.; Zotti, M.J.; Smagghe, G.; Christiaens, O. RNAi Efficiency, Systemic Properties and Novel Delivery Methods for Pest Insect Control: What We Know So Far. Front. Physiol. 2016, 7, 553. [CrossRef]

43. Palli, S.R. RNA Interference in Colorado Potato Beetle: Steps toward Development of DsRNA as a Commercial Insecticide. Curr. Opin. Insect Sci. 2014, 6, 1-8. [CrossRef] 
44. Prentice, K.; Christiaens, O.; Pertry, I.; Bailey, A.; Niblett, C.; Ghislain, M.; Gheysen, G.; Smagghe, G. RNAi-based Gene Silencing through DsRNA Injection or Ingestion against the African Sweet Potato Weevil Cylas Puncticollis (Coleoptera: Brentidae). Pest Manag. Sci. 2017, 73, 44-52. [CrossRef]

45. Ni, M.; Ma, W.; Wang, X.; Gao, M.; Dai, Y.; Wei, X.; Zhang, L.; Peng, Y.; Chen, S.; Ding, L. Next-generation Transgenic Cotton: Pyramiding RNAi and Bt Counters Insect Resistance. Plant Biotechnol. J. 2017, 15, 1204-1213. [CrossRef]

46. Tabashnik, B.E.; Carrière, Y. Surge in Insect Resistance to Transgenic Crops and Prospects for Sustainability. Nat. Biotechnol. 2017, 35, 926-935. [CrossRef] [PubMed]

47. Kim, Y.H.; Issa, M.S.; Cooper, A.M.; Zhu, K.Y. RNA Interference: Applications and Advances in Insect Toxicology and Insect Pest Management. Pestic. Biochem. Physiol. 2015, 120, 109-117. [CrossRef] [PubMed]

48. Vellichirammal, N.N.; Gupta, P.; Hall, T.A.; Brisson, J.A. Ecdysone Signaling Underlies the Pea Aphid Transgenerational Wing Polyphenism. Proc. Natl. Acad. Sci. USA 2017, 114, 1419-1423. [CrossRef]

49. Hussain, T.; Aksoy, E.; Çalışkan, M.E.; Bakhsh, A. Transgenic Potato Lines Expressing Hairpin RNAi Construct of MoltingAssociated EcR Gene Exhibit Enhanced Resistance against Colorado Potato Beetle (Leptinotarsa Decemlineata, Say). Transgenic Res. 2019, 28, 151-164. [CrossRef] [PubMed]

50. Zhu, J.-Q.; Liu, S.; Ma, Y.; Zhang, J.-Q.; Qi, H.-S.; Wei, Z.-J.; Yao, Q.; Zhang, W.-Q.; Li, S. Improvement of Pest Resistance in Transgenic Tobacco Plants Expressing DsRNA of an Insect-Associated Gene EcR. PLoS ONE 2012, 7, e38572.

51. Malik, H.J.; Raza, A.; Amin, I.; Scheffler, J.A.; Scheffler, B.E.; Brown, J.K.; Mansoor, S. RNAi-Mediated Mortality of the Whitefly through Transgenic Expression of Double-Stranded RNA Homologous to Acetylcholinesterase and Ecdysone Receptor in Tobacco Plants. Sci. Rep. 2016, 6, 38469. [CrossRef]

52. Yu, R.; Xu, X.; Liang, Y.; Tian, H.; Pan, Z.; Jin, S.; Wang, N.; Zhang, W. The Insect Ecdysone Receptor Is a Good Potential Target for RNAi-Based Pest Control. Int. J. Biol. Sci. 2014, 10, 1171. [CrossRef]

53. Kontogiannatos, D.; Kolliopoulou, A.; Swevers, L. 4 The 'Trojan Horse' Approach for Successful RNA Interference in Insects. In RNAi for Plant Improvement and Protection; CABI: Wallingford, UK, 2021; pp. 25-39.

54. Kolliopoulou, A.; Kontogiannatos, D.; Swevers, L. The Use of Engineered Plant Viruses in a Trans-Kingdom Silencing Strategy against Their Insect Vectors. Front. Plant Sci. 2020, 11, 917. [CrossRef] [PubMed]

55. Swevers, L.; Kontogiannatos, D.; Kolliopoulou, A.; Ren, F.; Feng, M.; Sun, J. Mechanisms of Cell Entry by DsRNA Viruses: Insights for Efficient Delivery of DsRNA and Tools for Improved RNAi-Based Pest Control. Front. Physiol. 2021, 1930. [CrossRef] [PubMed] 